\title{
FÓRUM SER PROFESSOR! UM ESPAÇO DE FORMAÇÃO CONTINUADA DE PROFESSORES NO ICB/UFG
}

\author{
Lorena Alves Moraes, Rones de Deus Paranhos, Adda Daniela lima \\ Figueiredo Echalar, Simone Sendin Moreira Guimaraes
}

\begin{abstract}
Resumo: O presente artigo é um relato de experiência de um projeto de extensão realizado no e por professores do Instituto de Ciências Biológicas (ICB) da Universidade Federal de Goiás (UFG) denominado "Fórum Ser Professor! Reflexões sobre o processo formativo na licenciatura em Ciências Biológicas" e objetiva expor as motivações, a organização das atividades, o processo de divulgação e uma síntese/ avaliação das atividades desenvolvidas em 2017, tendo ainda no horizonte, a discussão sobre a formação de professores no atual cenário político brasileiro. Em 2017 foram realizadas quatro atividades de extensão que envolveram 10 pessoas na organização, seis palestrantes e 85 participantes internos e externos à UFG. Os temas escolhidos para as palestras foram um ponto forte do evento, assim como, a participação dos alunos do curso de licenciatura em Ciências Biológicas, responsáveis por quase 65\% dos presentes nos quatro dias de atividades. Porém, ainda foi pequena a participação externa, em especial de professores da educação básica. Assim, para a continuidade do projeto, que se pretende anual, os investimentos em divulgação externa, em especial nas escolas, devem ser ampliados.
\end{abstract}

Palavras-chave: formação de professores; extensão; profissão docente.

\section{FORUM TO BE A TEACHER! A SPACE FOR CONTINUED TEACHER} FORMATION AT ICB / UFG

\footnotetext{
Abstract: This article is an experience report of an extension project carried out in and by professors of the Institute of Biological Sciences (ICB) of the Federal University of Goiás (UFG) called "Forum to be a teacher! Reflections on the formation process in the graduation in Biological Sciences" and aims to expose the motivations, the organization of activities, the dissemination process and a synthesis/evaluation of the activities carried out in 2017, and also on the horizon, the discussion about
} 
teacher formation in the current Brazilian political scenario. In 2017, four extension activities were carried out involving 10 people in the organization, six presenter and 85 participants both inside and outside the UFG. The topics chosen for the lectures were a strong point of the event, as well as the participation of the undergraduate students in Biological Sciences, responsible for almost $65 \%$ of those present in the four days of activities. However, there was still little external participation, especially of primary education teachers. Thus, for the continuity of the project, which is intended to be annual, investments in external dissemination, especially in schools, should be expanded.

Keywords: teacher formation; extension; career teacher.

¡FORO SER PROFESOR! UNO ESPACIO DE FORMACIÓN CONTINUA DE MAESTROS EN EL ICB/UFG

Resumen: El artículo actual es un informe de la experiencia de un proyecto de extensión logrado hacia dentro en el y por los profesores del Instituto de Ciencias Biológicas (ICB) de la Universidad Federal de Goiás (UFG) denominated “ ¡Foro Ser Profesor! Reflexiones sobre el proceso de formación en la licenciatura en Ciencias Biológicas" y lente sacar a la luz las motivaciones, la organización de las actividades, el proceso de popularization y una síntesis/evaluación de las actividades se desarrolló en 2017, todavía tend en el horizonte, la discusión sobre la formación en la escenografía política brasileña en curso de los profesores. En 2017 eran las cuatro actividades de extensión consumadas que involucraron a 10 personas en la organización, seis palestrantes y 85 participantes internos y externos a UFG. En el año 2017 se llevaron a cabo cuatro actividades de extensión con 10 personas en la organización, seis oradores y 85 participantes internos y externos a la UFG. Los temas para las conferencias fueron un punto fuerte del evento, así como la participación de los alumnos del curso de grado en Ciencias Biológicas, representan casi el 65\% de los presentes en los cuatro días de actividades. Sin embargo, fue participación extranjera aún poco, en particular de los docentes de educación básica. Por lo tanto, para la continuidad del proyecto, objetivo, las inversiones anuales en divulgación extranjera, especialmente en las escuelas, deberían extenderse.

Palabras clave: formación de profesores; extensión; profesión docente. 


\section{INTRODUÇÃO}

O presente artigo é um relato de experiência de um projeto de extensão realizado no e por professores do Instituto de Ciências Biológicas (ICB) da Universidade Federal de Goiás (UFG) denominado "Fórum Ser Professor! Reflexões sobre o processo formativo na licenciatura em Ciências Biológicas" (“Fórum Ser Professor!") e objetiva expor as motivações, a organização das atividades, o processo de divulgação e uma síntese/avaliação das atividades desenvolvidas em 2017, tendo ainda no horizonte, a discussão sobre a formação de professores no atual cenário político brasileiro.

A formação de professores, por diferentes perspectivas, tem sido um tema caro e, portanto, se constituído numa disputa em que de um lado estão os grandes conglomerados empresariais que crescem no Brasil e fazem da educação um produto a ser comercializado e; os organismos multilaterais internacionais que editam orientações para formação de professores de modo a atender os interesses do capital. Do outro lado, estão as universidades públicas que, quantitativamente, tem pouca contribuição com a formação de professores no Brasil, mas são importantes locus da resistência ao desmonte de políticas públicas de educação. Soma-se a essas universidades os movimentos sociais que tem como pauta a defesa de uma universidade que seja socialmente referenciada.

Há outros aspectos contextuais nos quais essa disputa está inserida. Daremos ênfase ao contexto reformista de políticas públicas brasileiras que pode favorecer uns dos disputantes em detrimento dos outros e que notoriamente incidirá de modo imediato e/ou mediato na formação de professores para a educação básica. São aspectos desse contexto: reforma do ensino médio; PEC $n^{\circ} 241 / 55$; projetos de lei que tramitam no congresso nacional para instituir o programa escola sem partido. Em síntese, são projetos que desenham uma escola com um projeto formativo alinhado a preceitos neoliberais e que, portanto, demanda um "novo" docente para essa escola. De acordo com Decker (2015), o Banco Mundial vê como impertinente uma formação de professor calcada no conhecimento científico e pedagógico, pois o mercado demanda uma formação prática e flexível. Essa autora ainda destaca que

A ideia da profissionalização docente traz para a escola conceitos do campo empresarial e pretende punir ou recompensar o professor de acordo com o desempenho aferido em avaliações. Este modelo pauta-se no controle da ação docente, na formação pela e para a prática, no desenvolvimento de competências (DECKER, 2015, p. 140). 
Percebemos no fragmento acima como a lógica empresarial permeia a profissionalização do professor e, por sua vez, pode constituir a pauta formativa de professores em nosso país. Face a esses aspectos, é possível perceber que a formação de professores deve ser tomada tanto na dimensão dos conhecimentos científicos das diferentes áreas do conhecimento quanto na sua faceta que é eminentemente política. Formar professores na sociedade de classe é posicionar-se com um projeto de sociedade que queremos e para isso, é necessário explicitar aos licenciandos os fundamentos e as contradições que perpassam os projetos reformistas que incidirão na profissão docente. Entendemos, como aponta Dalci e Agusti (2016), que assim sendo, estaríamos nos atentando às abordagens epistêmicas da universidade: a) pesquisa como possibilidade do novo e; b) formação política de cidadãos.

Sobre a primeira abordagem é necessário enfatizar que mesmo diante da destruição das condições materiais para a produção de conhecimento nesse país, as instituições de educação superior públicas, ainda constituem o principal locus de produção de conhecimento científico. No campo da pesquisa educacional e, sobretudo, da formação de professores as pesquisas têm denunciado os processos de erosão da profissão da profissão docente calcado em péssimas condições de ensino-aprendizagem, na não valorização do trabalho docente, nas insuficientes condições de formação continuada, dentre outros aspectos. Diante a isso, cabe questionar em que medida essas sinalizações incidem nos processos de formulação de políticas públicas de educação.

A reflexão sobre esse questionamento, em nossa leitura, acionaria a segunda abordagem epistêmica da universidade, ou seja, a da formação política. Dizemos isso, pois demandaria tomar a prática social da produção do conhecimento científico e de sua aprendizagem, tendo essa prática como ponto de partida e de chegada. Foi na dimensão da formação política que se instalaram todas as discussões realizadas no "Fórum Ser Professor!" sem marginalizar as relações com o conhecimento científico aprendido na universidade que ampliam, em largura e profundidade, a leitura da realidade bem como as possiblidades de nela intervir.

Segundo o FORPROEXT (2007, p. 17) “A extensão universitária é o processo educativo, cultural e científico que articula o ensino e a pesquisa de forma indissociável e viabiliza a relação transformadora entre a universidade e a sociedade." Logo, ela um meio viável de intervenção na realidade e, a propósito, a temática da formação de professores tem sido objeto de ações extensionistas 
em nosso país em que é possível perceber o destaque dado à formação continuada (HENRIQUES et al., 2016; DOMINGUINI, ROSSO e GIASSI, 2013; ROSA, 2013; GONÇALVES, MELLO e MELLO-CARPES, 2016; CAVAGIS et al., 2017; MORAIS, ARAÚJO e PRADO, 2012; SOUZA-JÚNIOR, BALDUINO e CUNHA, 2013). As atividades desenvolvidas nessas ações podem ser caracterizadas por cursos de capacitação de conteúdos específicos; cursos de capacitação para utilização de TIC e realização de oficinas. Há também ações de extensão que se ocuparam da formação inicial (HIRAMA, 2016; MELO, 2014; FERNANDES, 2014; SILVA et al, 2012) e as atividades foram o projeto de extensão para que os licenciandos desenvolvessem atrelando a isso as atividades da formação inicial; desenvolvimento de atividades em espaços não formais de ensino; atividades de extensão na relação com o PIBID.

A marca distintiva da atividade do projeto de extensão "Fórum Ser Professor!" é a leitura política da realidade da atuação profissional do professor de modo a proporcionar um encontro num espaço constituído para explicitar e discutir os enfrentamentos da profissão docente, tanto no contexto estadual quanto nacional, envolvendo os docentes que estão em exercício (rede estadual e municipal de educação), os que ainda estão no processo de formação inicial (licenciandos) e os professores formadores de professores. Nesse sentido, o "Fórum Ser Professor!" surgiu a partir de um conjunto de condições institucionais que permitiram a criação desse espaço de discussão e de formação política.

\section{HistóRICo DA AtividAde}

Em 2009 a Pró-Reitoria de Graduação (PROGRAD/UFG) divulgou o Edital PROGRAD / PRODOCÊNCIA nº 001/2009 para submissão de projetos de criação e/ou consolidação de Núcleos de Pesquisa ou Laboratórios que fortalecessem os cursos de licenciaturas da UFG. Nesse contexto, os professores da área da educação do Departamento de Biologia Geral do Instituto de Ciências Biológicas (ICB) submeteram um projeto para a criação do Laboratório de Estágio Curricular Supervisionado da Licenciatura em Ciências Biológicas. Em 2010 a proposta de criação do laboratório foi reorganizada para que o espaço também pudesse receber atividades desenvolvidas nas disciplinas de "Ensino de Ciências no Ensino Fundamental" e "Ensino de Biologia no Ensino Médio". 
Desta forma, foi organizado o Laboratório de Estágio Supervisionado e Ensino de Ciências - LESEC ${ }^{1}$ (UFG, 2018).

Já em 2012, com a intensificação da pesquisa, característica central do LESEC na atualidade, e para fortalecer as atividades relacionadas à formação de professores, os docentes que coordenavam as ações de pesquisa entenderam que a tríade basilar da universidade (extensão, pesquisa e ensino) poderia contribuir com a formação dos licenciandos em Ciências/Biologia, contemplando temas e estratégias metodológicas diferentes das utilizadas nas atividades de ensino e pesquisa. Assim, foi organizada uma atividade de extensão denominada "Fórum: Ser Professor! Reflexões sobre a formação no ICB/UFG”. Com três palestras organizadas, a atividade atendeu mais de 100 participantes entre alunos de graduação, pós-graduação e professores da educação básica. Em 2017 o "Fórum Ser Professor!" foi novamente submetido a Pró-Reitoria de Extensão e Cultura (PROEC) com intuito de transformar essa atividade em um projeto de extensão permanente no ICB/UFG, de modo a ampliar a discussão sobre o processo formativo do profissional da educação em todas as suas nuances.

Em relação às atividades de extensão, essas são consideradas ações mais difusa, menos hierárquicas e burocráticas. Seus programas de ensino não precisam necessariamente seguir um sistema sequencial e hierárquico de "progressão" e podem ter duração variável, concedendo ou não certificados de aprendizagem (SCHAFRANSKI, 2007). De acordo com as diretrizes do FORPROEXT (2007), suas atividades tendem a possuir interação dialógica, interdisciplinaridade, indissociabilidade ensino-pesquisa-extensão, impacto na formação dos envolvidos na ação, em especial aos estudantes e, finalmente impacto e transformação social.

A formação de professores é tarefa de todos dentro da estrutura universitária, não apenas dos professores da área de educação, do ensino ou da didática. Assim, as atividades de extensão universitária servem como um lugar de enfrentamento de lutas e de rompimento de fronteiras no processo de constituição dos saberes dos futuros professores (SILVA; ROSA, 2011).

\footnotetext{
O LESEC é um laboratório do ICB/UFG que congrega quatro professores do DEC (Departamento de Educação em Ciências) e atividades de pesquisa e ensino. Estão vinculados ao LESEC o Grupo de Pesquisa Colligat - (re)pensando a formação de professores de ciências e biologia; a REPEC-EJA (Rede de Pesquisa em Educação em Ciências para Educação de Jovens e Adultos); o PIBID Biologia (2014-2017) e o projeto de extensão "Fórum Ser Professor!".
} 


\section{Planejamento E Desenvolvimento das atividades}

Destarte, o "Fórum Ser Professor!" visa problematizar o contexto educacional brasileiro, por meio de ações que articulem a extensão, o ensino e a pesquisa de forma indissociável, integrando a universidade e a sociedade via escolas de educação básica e preferencialmente um de seus sujeitos: os professores. Na equipe executora além de docentes e alunos (graduação e pós-graduação) da UFG, a proposta conta com a participação da comunidade externa/sociedade, pois professores da educação básica também estão na organização dessa atividade.

Com atividades mensais entre agosto/2017 e julho/2018 essa proposta de extensão foi organizada para suscitar discussões que vão desde os dilemas da formação inicial, passando pelos aspectos da profissionalização e identidade docente a temas sócio culturais que desafiam a prática profissional do professor na escola.

Um olhar especial foi dado às discussões que envolvem os aspectos políticos da formação dos professores de Ciências/Biologia considerando o cenário da educação no Brasil a partir de: a) Diretrizes Curriculares Nacionais (Res. CNE/CP no 002/2015); b) Reforma do ensino médio (MP $n^{\circ} 746 / 2016$ ); c) Projeto de Lei 7.180/2014 que intenta alterar o art. $3^{\circ}$ da Lei de Diretrizes e Bases da Educação (LDB) no 9.394/96, no sentido de dar precedência aos valores de ordem familiar sobre a educação escolar nos aspectos relacionados à educação moral, sexual e religiosa; d) Os Projetos de Lei ${ }^{\circ}$ 867/2015 e $n^{\circ}$ 193/2016 que visam incluir entre as diretrizes e bases da educação nacional o "Programa Escola sem Partido"; e) Projeto de Lei no 1.411/2015 que tipifica o crime de assédio ideológico na medida em que busca alterar o Decreto Lei $\mathrm{n}^{\circ}$ 2.848/1940 (Código Penal Brasileiro) e a Lei $\mathrm{n}^{\circ}$ 8.069/1990 (Estatuto da Criança e do Adolescente); f) a Base Nacional Comum Curricular (BNCC) que estabelece os direitos, os conhecimentos, as competências e os objetivos de aprendizagem para Educação Básica, entre outras temáticas.

Além disso, considerando os pareceres CNE/CP no 9/2001, CNE/CP n ${ }^{\circ}$ 21/2001, CNE/CP no 28/2001 e CNE/CES no 15/2005 e Resoluções CNE/CP $n^{\circ} 1 / 2002$ e CNE/CP no 2/2002 que versam sobre a Prática como Componente Curricular (PCC), podemos indicar que outra atenção do "Fórum Ser Professor!", já em ação endógena ao curso, será o acompanhamento das atividades relacionadas às PCC desenvolvidas na licenciatura em Ciências Biológicas do 
ICB. Como uma atividade ímpar na formação de professores, as PCC (implementadas no referido curso em 2015) carecem ainda serem discutidas e avaliadas. Assim, atividades de formação (palestras, mesas redondas, etc) específicas sobre a temática, bem como a organização de momentos de socialização dos resultados das práticas desenvolvidas pelos professores, também, constituirão atividades preferenciais desse Projeto.

Os dados que apresentaremos neste trabalho referem-se ao processo de construção da identidade do "Fórum Ser Professor!" e uma análise inicial das primeiras quatro ações desenvolvidas em 2017.

\section{O Processo de implementação do “Fórum: Ser Professor!”}

As palestras foram organizadas para serem desenvolvidas mensalmente e ocorrerem no auditório do ICB IV no horário das $17 \mathrm{~h} 30 \mathrm{~min}$. às $19 \mathrm{~h}$ ou das $12 \mathrm{~h}$ àss $13 \mathrm{~h} 30 \mathrm{~min}$. intercalando os meses/horários para atender demandas de alunos do curso de licenciatura em Ciências Biológicas, integral e noturno, e de professores que trabalham em diferentes turnos.

Os temas foram escolhidos considerando á relevância das PCC do curso (demanda interna), bem como as demandas trazidas pelos professores da educação básica e alunos da pós-graduação (demanda externa). O quadro a seguir, apresenta os temas de todos os encontros e os palestrantes das atividades que já foram realizadas.

Quadro1: Datas/Temas Selecionados/Palestrantes

\begin{tabular}{|c|c|c|}
\hline MÊS & TEMA & Palestrante \\
\hline SETEMBRO & $\begin{array}{c}\text { A PRÁTICA COMO COMPONENTE } \\
\text { CURRICULAR (PCC) - A LECISLAÇÃO } \\
\text { ATUAL }\end{array}$ & Prof. MS. JosÉ Firmino Neto \\
\hline OUTUBRO & $\begin{array}{c}\text { OS ESTATUTOS DO CONHECIMENTO } \\
\text { BIOLÓCICO E A FORMAÇÃO DE } \\
\text { PROFESSORES }\end{array}$ & $\begin{array}{c}\text { Prof. Dr. ANTÔNIO F. DO NASCIMENTO } \\
\text { JUNIOR }\end{array}$ \\
\hline NOVEMBRo & $\begin{array}{c}\text { A PRÁTICA COMO COMPONENTE } \\
\text { CURRICULAR - ALCUMAS EXPERIÊNCIAS } \\
\text { DA UFG }\end{array}$ & 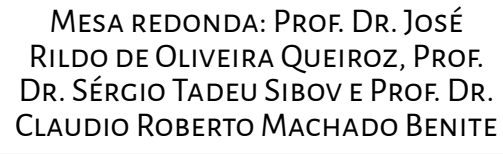 \\
\hline DEZEMBRO & $\begin{array}{l}\text { ORGANIZAÇÕES SOCIAIS (OS) E } \\
\text { MILITARIZAÇÃO NA ESCOLA }\end{array}$ & $\begin{array}{c}\text { Profa. Dra. JANE DARLEY AlVES dos } \\
\text { SANTOS }\end{array}$ \\
\hline
\end{tabular}

FONTE: ELABORAÇÃO DOS AUTORES 
Nesse primeiro momento do projeto, foram organizadas três palestras e uma mesa redonda. A primeira palestra se constituiu em uma exposição introdutória sobre os aspectos legais e pedagógicos das PCC. O palestrante abordou o histórico legal de 2002 até 2015 indicando também como essa atividade estava sendo implementada em outras universidades/cursos do estado de Goiás. O palestrante retomou dados de sua pesquisa de mestrado e apresentou um panorama sobre as PCC nas graduações goianas. Em um momento de sua fala ele retoma a seguinte conclusão de sua pesquisa:

Assim, a PPC contribui para a superação da dicotomia entre conhecimento pedagógico e específico, na medida em que busca a confluência destes saberes, o que é fundamental para a superação da dicotomia entre teoria-prática e assim a constituição da práxis. A ideia de práxis não é evidenciada no interior dos PPC's, em suma, ficando apenas evidente em alguns pontos a relação de unidade entre teoria-prática. Os cursos devem entender que a prática é o ponto de partida e chegada do trabalho docente, oportunizando uma formação pautada em uma racionalidade crítica, na qual o saber-fazer docente está imbricado ao exercício de reflexão e autorreflexão, que contenha em si uma intencionalidade (OLIVEIRA NETO, 2016, p. 116)

A segunda palestra foi relacionada a aspectos teóricos-conceituais da Biologia, enquanto Ciência numa perspectiva filosófica. Amparado numa abordagem relacionada à História e Filosofia da Ciência (HFC), a palestra explorou os estatutos conceitual, epistemológico, ontológico e histórico-social da Biologia. Para Nascimento Jr. (2010), a noção de estatuto se refere a um conjunto de atributos que compõem a constituição da Ciência, no caso da Biologia. No que diz respeito ao objeto ou fenômeno investigado e explicado, seu estudo e processo de ensino-aprendizagem deve estar pautado em princípios que elucidem o processo de construção do conhecimento científico (leis, métodos, modelos etc.), o contexto histórico-social no qual o processo de construção da ciência ocorreu, bem como do conjunto de teorias, conceitos, símbolos e significados sobre a natureza e seus elementos.

$\mathrm{O}$ terceiro encontro foi uma mesa-redonda na qual se reuniram representantes das três licenciaturas em Ciências da Natureza da UFG - Regional Goiânia (Química, Física e Biologia) para discutir os procedimentos de implementação das PCC nos três cursos de graduação, enfatizando a relação dessas práticas com os fundamentos teóricos dos referidos cursos de licenciatura. Finalmente, o quarto encontro se constituiu de uma palestra centrada 
na formação política dos professores e licenciandos em formação na qual a pesquisadora apresentou uma rica discussão relacionada ao processo de implementação das Organizações Sociais (OS) e de militarização das escolas públicas estaduais em Goiás. O ponto forte dessa atividade foi o relato da atuação dos alunos secundaristas do estado diante desse processo.

Em relação à caracterização dos palestrantes, esses foram escolhidos pela relação com a temática do evento e pela disponibilidade de participação nas datas indicadas. Um palestrante era doutorando e todos os outros doutores com experiência nas temáticas em questão. A seguir (Quadro 2) segue uma breve descrição da formação e filiação institucional dos palestrantes.

Quadro 2: Palestrantes/ Formação/Filiação Institucional

\begin{tabular}{|c|c|c|}
\hline Palestrante & FORMAÇÃO & FILIAÇÃO INSTITUCIONAL \\
\hline $\begin{array}{l}\text { PROF. MS. JosÉ } \\
\text { FIRMINO NETO }\end{array}$ & $\begin{array}{c}\text { É GRADUADO EM CIÊNCIAS BIOLÓCICAS } \\
\text { E EM PEDACOGIA. ESPECIALISTA EM } \\
\text { FORMAÇÃO EM EDUCAÇÃO À DISTÂNCIA. } \\
\text { MESTRE E DOUTORANDO EM EDUCAÇÃO } \\
\text { EM CIÊNCIAS E MATEMÁTICA. }\end{array}$ & $\begin{array}{c}\text { ATUALMENTE É PROFESSOR } \\
\text { EFETIVO DA REDE MUNICIPAL } \\
\text { DE GOIÂNIA. }\end{array}$ \\
\hline $\begin{array}{l}\text { PROF. DR. ANTÔNIO } \\
\text { F. DO NASCIMENTO } \\
\text { JUNIOR }\end{array}$ & $\begin{array}{c}\text { É GRADUADO EM CIÊNCIAS BIOLÓGICAS } \\
\text { E MESTRE EM CIÊNCIAS. DOUTOR EM } \\
\text { EDUCAÇÃO PARA A CIÊNCIA E DOUTOR EM } \\
\text { CIÊNCIAS BIOLÓCICAS (GENÉTICA). }\end{array}$ & $\begin{array}{l}\text { ATUALMENTE É PROFESSOR } \\
\text { ADJUNTO DA UNIVERSIDADE } \\
\text { FEDERAL DE LAVRAS }\end{array}$ \\
\hline $\begin{array}{l}\text { PROF. DR. JOSÉ } \\
\text { RILDO DE OLIVEIRA } \\
\text { QUEIROZ }\end{array}$ & $\begin{array}{l}\text { É GRADUADO, MESTRE E DOUTOR EM } \\
\text { FíSICA. }\end{array}$ & $\begin{array}{c}\text { ATUALMENTE É PROFESSOR } \\
\text { ADJUNTO DA UFC NO } \\
\text { INSTITUTO DE FÍSICA (IF) }\end{array}$ \\
\hline $\begin{array}{l}\text { Prof. Dr. SÉRGio } \\
\text { TADEU SIBOV }\end{array}$ & $\begin{array}{c}\text { É GRADUADO EM CIÊNCIAS BIOLÓCICAS, } \\
\text { MESTRE DOUTOR EM GENÉTICA E BIOLOGIA } \\
\text { MOLECULAR. }\end{array}$ & $\begin{array}{l}\text { ATUALMENTE É PROFESSOR } \\
\text { ADJUNTO DA UFG NO } \\
\text { INSTITUTO DE CIÊNCIAS } \\
\text { BIOLÓCICAS (ICB) }\end{array}$ \\
\hline $\begin{array}{l}\text { Prof. DR. CLAUdio } \\
\text { R. M. BENITE }\end{array}$ & $\begin{array}{c}\text { É GRADUADO EM QUÍMICA, ESPECIALISTA } \\
\text { EM ENSINO DE CIÊNCIAS, MESTRE EM } \\
\text { EDUCAÇÃO EM CIÊNCIAS E MATEMÁTICA } \\
\text { E DOUTOR EM QUÍMICA COM ÊNFASE EM } \\
\text { ENSINO DE QUÍMICA. }\end{array}$ & $\begin{array}{l}\text { ATUALMENTE É PROFESSOR } \\
\text { ADJUNTO DA UFC NO } \\
\text { INSTITUTO DE QUÍMICA (IQ) }\end{array}$ \\
\hline $\begin{array}{l}\text { PROFA. DRA. JANE } \\
\text { DARLEY ALVES DOS } \\
\text { SANTOS }\end{array}$ & $\begin{array}{c}\text { É GRADUADA EM QUÍMICA, MESTRE EM } \\
\text { EDUCAÇÃO EM CIÊNCIAS E MATEMÁTICA E } \\
\text { DOUTORA EM QUÍMICA, COM ÊNFASE EM } \\
\text { ENSINO DE QUÍMICA. }\end{array}$ & $\begin{array}{c}\text { ATUALMENTEÉ } \\
\text { COLABORADORA DA } \\
\text { UNIVERSIDADE FEDERAL EM } \\
\text { DOIS GRUPOS DE ESTUDOS/ } \\
\text { PESQUISA. }\end{array}$ \\
\hline
\end{tabular}

FONTE: ELABORAÇÃO DOS AUTORES

Consideramos que a experiência dos palestrantes foi um ponto importante para fortalecer as palestras. Todos os envolvidos tinham compromisso com a temática para a qual foi convidado e mediou com sucesso as relações entre os 
conhecimentos acadêmicos, produzidos na universidade e experiências sociais vivenciadas por eles, pelos estudantes e docentes que participaram da atividade.

Em relação à divulgação, para atingir o maior numero de sujeitos, tanto relacionados aos alunos do curso quanto de professores da educação básica, solicitamos a Assessoria de Comunicação (ASCOM) da UFG a identidade visual do projeto, que após discutido no coletivo dos organizadores do evento, ficou como apresentado na Figura 1.

FicuRA 1: Logo criado para a atividade de extensão

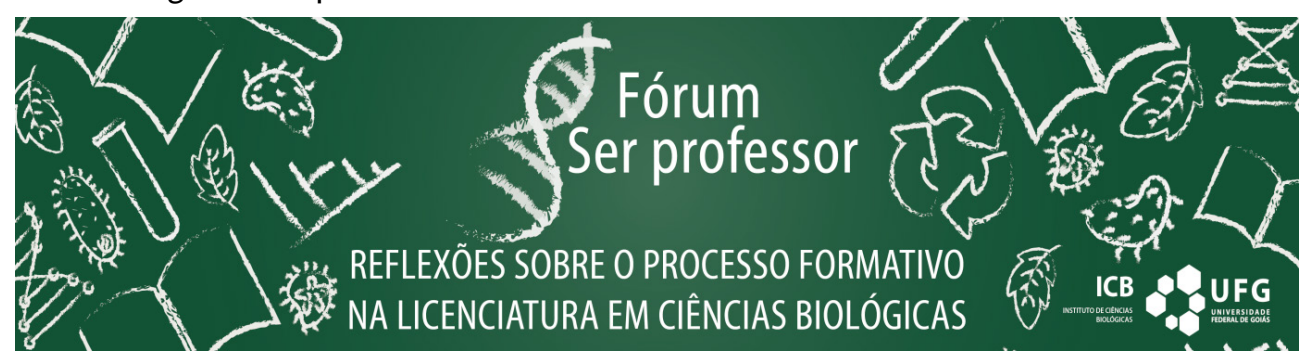

FONTE: PRODUZIDO PELA ASCOM/UFG

Essa identidade visual foi pensada para que envolvesse tanto elementos gráficos relacionados à educação e ao fazer docente, como livros e um "quadro negro"; quanto da Biologia, como figuras de moléculas de DNA, folhas, tubos de ensaio, etc. Além disso, essa identidade está relacionada à identidade visual do LESEC, laboratório ao qual esse projeto de extensão está vinculado. Ela foi utilizada na divulgação virtual, em banners, bottons e certificados do evento.

Foram constituídas duas formas de divulgação das ações do projeto: a) Interna à UFG: promoção do evento pela própria ASCOM no e-mail dos professores da instituição, por meio dos grupos de whatsapp e da divulgação em um grupo fechado da coordenação do ICB no Facebook; b) Externa à UFG: criação de eventos públicos em uma rede social para divulgação das ações a cada mês.

\section{ANÁLISE PARCIAL DO PROJETO EM ANDAMENTO}

Depois de pensar sobre o objetivo formativo da atividade de extensão, sobre a perspectiva teórica da ação, proceder a escolha das temáticas, indicar os palestrantes e realizar quatro (quatro) atividades formativas das 10 pensadas para 2017/2018, é possível realizar uma análise parcial do "Fórum Ser Professor!”. 
O projeto envolveu na sua equipe de elaboração dez sujeitos, quatro professores do DEC/ICB, uma aluna voluntária PROEC, um aluno de graduação (licenciatura em Ciências Biológicas), dois mestrandos do Programa de Pós-graduação em Educação em Ciências e Matemática (UFG) e duas professoras da educação básica, vinculadas às escolas estaduais de Goiás.

A atividade também envolveu seis professores que ministraram três palestras e compuseram uma mesa redonda. Nos quatro encontros de 2017 contamos com 85 participantes, sendo 50 do sexo feminino e 35 do sexo masculino. Numa perspectiva quantitativa o Figura 2 apresenta a participação dos sujeitos nas atividades oferecidas.

FicuRa 2 - Número de participantes por atividade

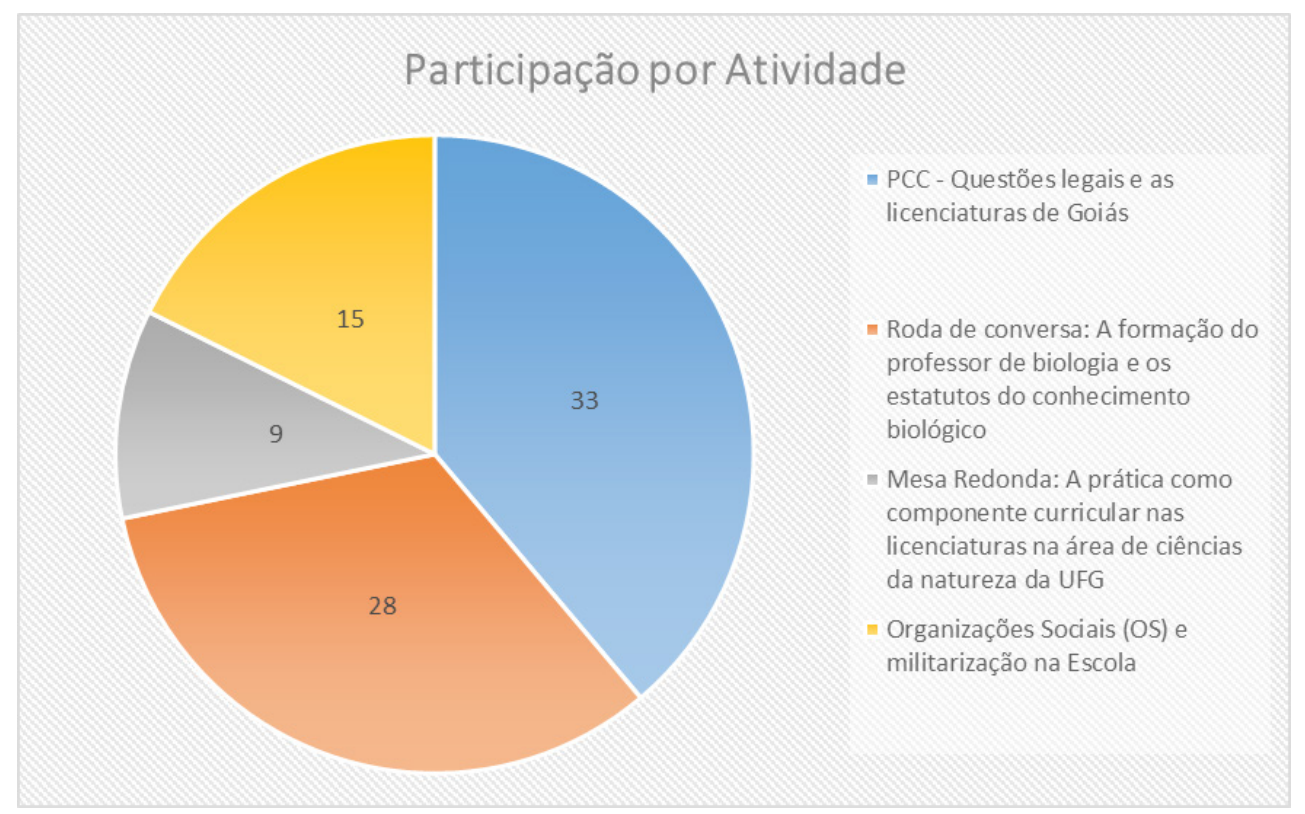

FONTE: ELABORAÇÃO DOS AUTORES

É possível perceber que os eventos que mais tiveram participação foram as duas primeiras palestras. Acreditamos que isso se deve a fatores que estão relacionados ao período do semestre e a natureza da palestra. A primeira palestra aconteceu em setembro, momento em que os alunos estão mais envolvidos com atividades que não são provas e ou entrega de trabalhos. Já a segunda, além de estar em um momento no qual ainda não se acumulam provas e o fechamento do semestre letivo foi realizada num sábado de manhã 
para aproveitar a visita de um palestrante externo vindo para outro evento ${ }^{2}$. Já as duas últimas atividades foram realizadas no fechamento do semestre e os alunos/professores e pós-graduandos já estavam envolvidos com as atividades de encerramento de semestre.

Numa análise mais qualitativa, independente no número de participantes, pudemos perceber que as atividades que mais suscitaram debates e perguntas foram as duas que tiveram temáticas relacionadas às PCC (primeira e terceira atividades). Talvez pelo público ser composto em grande parte por alunos e professores da universidade, em especial do curso de licenciatura em Ciências Biológicas (Figura 3) que estão atualmente vinculados a uma matriz que pela primeira vez inclui essa atividade no PPC (Projeto Político do Curso) ${ }^{3}$.

Nesse contexto e pelas atividades propostas, percebemos que ainda são muitas as inquietações legais e pedagógicas em relação à temática. É importante destacar que mesmo se considerarmos que, do ponto de vista legal, desde 2002 a resolução CNE/CP no 2 de 19 de fevereiro de 2002 já instituía a "Prática como Componente Curricular" (PCC) como atividade obrigatória para formação de professores, o curso de Licenciatura em Ciências Biológicas da UFG apenas em 2015, com a reformulação do seu PPC em atendimento a resolução do CNE/CP no 2 de $1^{\circ}$ de Julho de 2015 que define as Diretrizes Curriculares Nacionais para a formação inicial em nível superior inclui a PCC na formação de seus licenciandos.

Nessa resolução, que baliza hoje a formação de professores no país, a PCC aparece como 400 (quatrocentas) horas de atividade obrigatória que deve ser distribuída ao longo de todo processo formativo. Assim, em virtude da pouca clareza da legislação bem como da recente inclusão dessas práticas no PPC do curso em questão essa atividade motivou muita participação de licenciandos e professores do curso.

2 O Prof. Dr. Antônio Fernandes do Nascimento Junior proferiu a palestra de encerramento do II Simpósio do Pidid Biologia da UFG (II SPBU), participando no dia seguinte do "Fórum Ser Professor!”.

3 Em 2015 foi implementado o novo PPC do Curso de Licenciatura em Ciências Biológicas do ICB/ UFG e pela primeira vez o projeto do curso incluiu as 400 horas de Prática como Componente Curricular. 
Ficura 3 - Filiação dos participantes do "Fórum Ser professor!"

\section{Filiação dos Participantes}

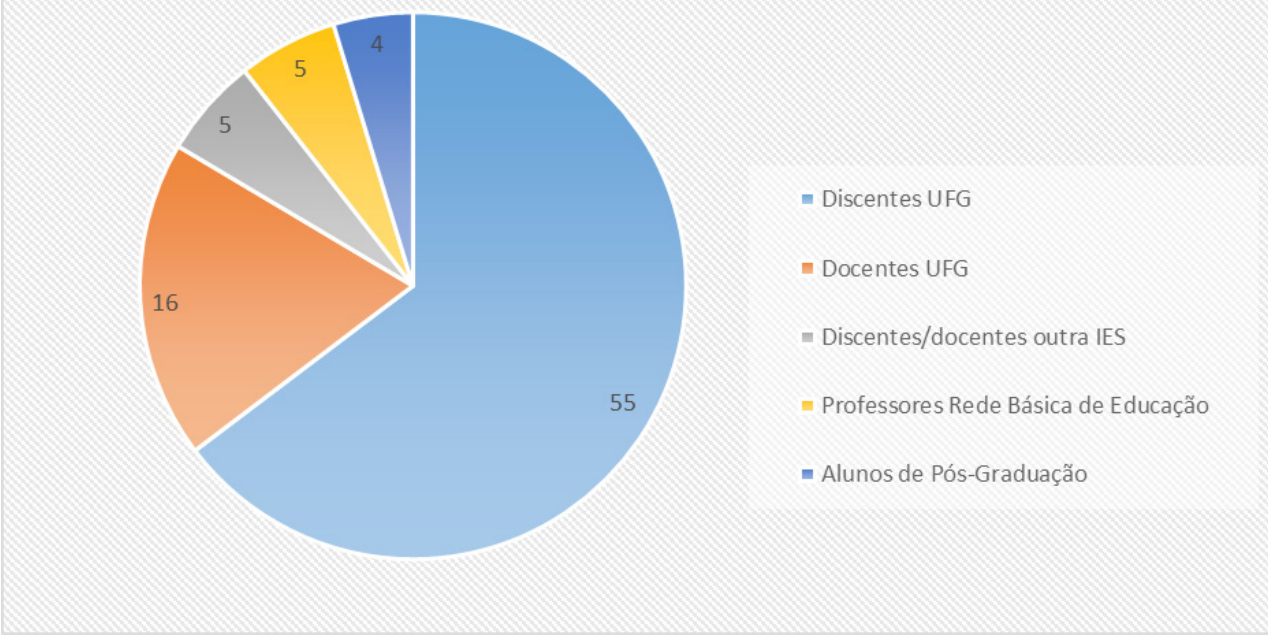

FONTE: ELABORAÇÃO DOS AUTORES

As outras duas atividades (segunda e quarta palestras) foram mais formativas no sentido de fundamentar teoricamente os alunos e demais participantes em temas atuais e caros para formação teórica e política dos docentes e futuros docentes que lá estavam. Um destaque importante, característicos das palestras dois e quatro, é que a participação de professores da educação básica, embora quantitativamente pequena, foi qualitativamente muito importante. As perguntas, contextualizadas com o "chão da escola", provocaram reflexões críticas em todos os envolvidos e propiciaram a troca de experiência entre a academia-escola que são pequenas em outras atividades da universidade, mas que se materializam mais intensamente nas atividades de extensão universitária. Assim, entendemos que a escolhas das temáticas em questão foi acertada fazendo com que o evento atendesse seu objetivo formativo.

Neste primeiro semestre de atividade do "Fórum Ser professor!", ainda foi composto essencialmente por alunos e docentes da UFG. Isso é um ponto que precisa ser superado para que o objetivo de extensão das universidades realmente se concretize. De acordo com o Artigo $n^{\circ} 2$ da resolução CONSUNI n ${ }^{\circ}$ 03/2008 da UFG o objetivo geral de uma ação de extensão é "promover entre a universidade e a sociedade, a interação dos saberes, procurando, nesse processo, socializar a cultura e o conhecimentos acadêmicos e, ao mesmo tempo, enriquecer-se com os saberes extra-acadêmicos". (UFG, 2008, p. 1). A baixa 
participação (do ponto de vista quantitativo) da comunidade que extrapole alunos e professores da UFG ainda não possibilita materializar na sua integralidade esse objetivo, porém, por hora atendemos o Artigo no 4 no que se relaciona a articulação entre ensino e pesquisa.

\section{Considerações Finais}

Historicamente a formação de professores no Brasil não tem recebido a atenção que merece, palco de disputas que envolvem grandes conglomerados empresariais e organismos multilaterais internacionais de um lado e do outro lado as universidades públicas, que mesmo em situações políticas adversas são importantes locus da resistência ao desmonte das políticas públicas de educação. Pensando nessa importância o "Fórum Ser Professor!" persegue o objetivo de ser mais um espaço de resistência dentro dessa instituição formativa. Para isso, procurou organizar palestras e mesas redondas que congregassem temas caros à formação inicial e continuada de professores.

Nesse primeiro semestre do projeto de extensão, é possível considerar que, de maneira geral o objetivo formativo proposto foi alcançado. O processo de elaboração coletivo envolvendo alunos de graduação, pós-graduação e professores da rede básica de ensino e professores da universidade deu ao projeto um olhar mais amplo que resultou em boas escolhas de temas, dias, horários, etc. Percebemos que os temas escolhidos para as palestras foram um ponto forte do evento, assim como a capacidade acadêmica dos palestrantes convidados.

Outro ponto positivo foi a participação dos alunos do curso de licenciatura em Ciências Biológicas, um grupo responsável por quase $65 \%$ dos presentes nos quatro dias de atividades. Essa foi uma mobilização interessante, se considerarmos que o projeto está em seu início e o horário nunca consegue atender a todos (curso integral e noturno). Porém, ainda foi pequena a participação externa, em especial de professores da educação básica, assim, para a continuação do projeto, que se pretende anual, investimentos em divulgação externa nas escolas deve ser ampliada. Além disso, os horários e dias da semana serão fixos em função de tornar a atividade periódica e os professores possam se organizar para participar.

Acreditamos no potencial formativo das atividades de extensão, pois em consonância ao apresentado por Kochnan e Curado (2016, p. 290) entendemos que 
A extensão é uma práxis quando entendida como uma ação transformadora, com bases sólidas, tanto teórica quanto metodológica, visando a emancipação do ser humano. Uma universidade que visa cumprir com seu papel social para além da produção do conhecimento, pela pesquisa, realiza a socialização de suas elaborações, por meio das ações de extensão.

No ensejo de uma formação integral de homem para uma sociedade mais justa e igualitária, compreendemos que o processo educativo deve oportunizar ao estudante o desenvolvimento intelectual, por meio dos conhecimentos científicos o desvelar do mundo e a transformação de todos indivíduos em sujeitos autônomos do seu conhecimento, por sua emancipação. Neste contexto a indissociabilidade entre ensino-pesquisa-extensão é necessário ao homem emancipado, logo em todo seu processo formativo.

\section{REFERÊNCIAS}

ANDRADE, M. L. S.; CORAIS, M. C. Formação continuada e profissionalização da docência. Interagir: pensando a extensão, n.3, p.27-36, jan./jul., 2003.

BRASIL, Lei no 9.394, de 20 de dezembro de 1996 (Lei de Diretrizes e Bases da Educação Nacional), MEC/Brasília, 1996.

Conselho Nacional de Educação. Define as Diretrizes Curriculares Nacionais para a formação inicial em nível superior (cursos de licenciatura, cursos de formação pedagógica para graduados e cursos de segunda licenciatura) e para a formação continuada. Resolução CNE/CP n. 02/2015, de $1^{\circ}$ de julho de 2015. Brasília, Diário Oficial [da] República Federativa do Brasil, seção 1, n. 124, p. 8-12, 02 de julho de 2015.

. Câmara dos Deputados. Projeto de Lei 7.180/2014 - Respeito às convicções do aluno, de seus pais ou responsáveis, tendo os valores de ordem familiar precedência sobre a educação escolar nos aspectos relacionados à educação moral, sexual e religiosa, vedada a transversalidade ou técnicas subliminares no ensino desses temas. 2014. Disponível em: <http://www.camara.gov.br/sileg/integras/1232338.pdf> Acesso em: 15 abr. 2017.

Câmara dos Deputados. Projetos de Lei no 867/2015 - Inclui, entre as diretrizes e bases da educação nacional, o “Programa Escola sem Partido”. 2015 Disponível em: <http://www.camara.gov.br/proposicoesWeb/fichadetramitacao?idProposic $\mathbf{a o}=\mathbf{1 0 5 0 6 6 8}>$ Acesso em: 15 abr. 2017.

Câmara dos Deputados. Projeto de Lei no 1.411/2015 - Tipifica o crime de Assédio Ideológico e dá outras providências. 2015. Disponível em: <http://www.camara. gov.br/proposicoesWeb/fichadetramitacao?idProposicao $=\mathbf{1 2 2 9 8 0 8}>$ Acesso em: 15 abr. 2017. 
Ministério da Educação. Base Nacional Comum Curricular (BNCC) - Documento preliminar. MEC. Brasília, DF, 2015. Disponível em: <http://basenacionalcomum.mec.gov.br/> Acesso em: 15 abr. 2017.

Ministério da Educação. Parecer CNE/CP 9, de 8 de maio de 2001. Documenta, Brasília, n. 476, p. 513-562, 2001a. Disponível em: <http://portal.mec.gov.br/cne/arquivos/pdf/028.pdf >. Acesso em: 23 out. 2006.

Ministério da Educação. Parecer CNE/CP n. 21, de 6 de agosto de 2001. Brasília, DF, 2001b. Disponível em: <http://portal.mec.gov.br/dmdocuments/cnecp_212001.pdf> . Acesso em: 23 out. 2006.

Ministério da Educação. Parecer CNE/CP n. 28, de 2 de outubro de 2001. Brasília, DF, 2001c. Disponível em: <http://portal.mec.gov.br/dmdocuments/cnecp_212001. pdf $>$. Acesso em: 23 out. 2006.

. Ministério da Educação. Resolução CNE/CP n. 1, de 18 de fevereiro de 2002. Diário Oficial da União, Brasília, 4 mar. 2002a. Seção 1. p. 8.

Ministério da Educação. Resolução CNE/CP n. 2, de 19 de fevereiro de 2002. Diário Oficial da União, Brasília, 4 mar. 2002b. Seção 1. p. 9.

Ministério da Educação. Parecer CNE/CES n. 15, de 2 de fevereiro de 2005. Brasília: MEC/CNE, 2005.

CAVAGIS, A. D. M.; JUNIOR, J. B. dos S.; KONDO, M. M.; BENEDETTI FILHO, J. V. G. E. Formação continuada de professores do Ensino Fundamental I em ciências da natureza e matemática. Rev. Ciênc. Ext. v.13, n.3, p. 146-159, 2017.

DALCIN, L.; AUGUSTI, R. B. O princípio da indissociabilidade entre ensino, pesquisa e extensão como paradigma de uma universidade socialmente referenciada. Rev. ELO Diálogo em Extensão, v. 5, n.3, dez., p.38-49, 2016.

DOMINGUINI, L.; ROSSO, P.; GIASSI, M. G. Extensão e a formação continuada de professores: um estudo de caso em Ciências Naturais. Rev. Ciênc. Ext. v. 9, n. 1, p. 124-134, 2013.

FERNANDES, C. P.; MONZAMBANI, B. A.; BENEDETTI-FILHO, E.; SANTOS JÚNIOR, J. B. dos; CAVAGIS, A. D. M. PIBID: um canal de extensão universitária para o ensino de ciências. Cidadania em Ação: Rev. Ext. e Cult., v. 8, n. 2, p. 1-13, 2014.

FORPROEXT. Fórum de Pró-Reitores de Extensão das Universidades Públicas Brasileiras. Extensão Universitária: organização e sistematização. Edison José Corrêa (Org.). Coordenação Nacional do FORPROEX. Belo Horizonte: Coopmed, 2007. 112p

GONÇALVES, R.; MELLO, E. M. B.; MELLO-CARPES, P. B. Oficina "Circuito Sensorial" como metodologia utilizada na formação continuada de professores de ciências - um relato de experiência. Rev. Ciênc. Ext. v.12, n.1, p.6-13, 2016. 
HENRIQUES, L. R.; KONIG, I. F. M.; DIAS, B. K. de M.; BAGNO, F. F.; SANTOS, R. C. V.; LEITE, J. P. V. Bioquímica nas escolas: uma estratégia educacional para o estudo de Ciência no Ensino Médio. Rev. ELO - Diálogo em Extensão, v. 5, n.3, dez., p.6-17, 2016. HIRAMA, L. K.; MATOS, J. A. de; JOAQUIM, C. dos S.; MONTAGNER, P. C. Extensão universitária e formação do professor de educação física: contribuições a partir da permanência prolongada. Rev. Ciênc. Ext. v.12, n.1, p.28-40, 2016.

KOCHHANN, A. M.; SILVA, K. A. C. P. C. A formação de professores no curso de pedagogia: perspectivas e limites da extensão universitária. Anais da V Semana de Integração. Inhumas: UEG, 2016, p. 286-296

MELO, J. S. A.; MONTEIRO, B. A. P.; CARVALHO, F. C. de; PINTO, L. de M. A.; SOARES, A. M. O museu de história natural da UFLA como espaço de divulgação científica e a formação inicial de professores. Rev. Extendere, v. 2, n. 1, jan./jun., p.149-165, 2014. MORAIS, J. F. S; ARAÚJO, M. S.; PRADO, G. V. Extensão e formação docente na escola: projetos em diálogo. Extensio: R. Eletr. de Extensão, v. 9, n. 13, p.91-105, 2012.

NASCIMENTO JÚNIOR, A. F. Construção de Estatutos de Ciência para a Biologia numa perspectiva histórico-filosófica: uma abordagem estruturante para seu ensino. Tese (Doutorado em Educação para a Ciência). Universidade Estadual Paulista - Júlio de Mesquita Filho, Campus de Bauru, 2010. 437 p.

OLIVEIRA NETO, J. F. Configurações da prática como componente curricular nos cursos de licenciatura em Ciências Biológicas de universidades públicas de Goiás: sentidos e implicações. 2016. 134 f. Dissertação (Mestrado em Educação em Ciências e Matemática) - Universidade Federal de Goiás, Goiânia, 2016.PAIVA, J. Formação continuada de professores: tramas da extensão em projetos de reformulação curricular. Interagir: pensando a extensão, n.3, p.37-45, jan./jul., 2003.

RODIRGUES, M. A. Atividades de extensão em locais de educação não formal para enriquecer a formação dos licenciandos em física. Em Extensão, v. 13, n. 1, p. 126-136, jan. / jun. 2014.

ROSA, L. S.; GONÇALVES, R.; RODRIGUES, T.; FAGUNDES, F. M.; TIEPPO, K.; ISOTON, M.; RIBEIRO, P. da S.; CARPES, F. P.; MELLO, E. M. B.; MELLO-CARPES, P. B. Difusão da fisiologia através da capacitação de docentes da educação básica. Rev. Ciênc. Ext. v.9, n.2, p.128-140, 2013.

SCHAFRANSKI, M. D. Educação não-formal e alfabetização de adultos: um relato de experiência. Revista Conexão. Ponta Grossa, v. 3, n. 1. 2007. Disponível em: <http:// www.uepg.br/revistaconexao/revista/edicao03/artigo5.pdf >. Acesso em 22 dez. 2012. SILVA, R. F.; ROSA, M. M. C. S. Extensão universitária no currículo das licenciaturas: inovação e relação de sentido. Olhar de Professor. Ponta Grossa, v. 14, n. 2, p. 371-380, 2011. 
SILVA, A. P.; FERNANDES, G.; COSTA, M. R. da.; NEVES, M. L. R. da C. Formação continuada de professores de biologia: uma proposta para complementar a educação em Diamantina, Minas Gerais. Em Extensão, v. 11, n. 2, p. 126-136, jan. / jun. 2012 SOUZA-JUNIOR, A. J. S.; BALDUINO, G. E.; CUNHA, M. D. Saberes docentes relativos à prática de calcular no processo de formação continuada de profissionais que atuam no ensino fundamental. Em Extensão, v. 12, n. 1, p. 24-41, jan. / jun. 2013.

UFG, Laboratório de Estágio Supervisionado e Ensino de Ciências - LESEC (Instituto de Ciências Biológicas - ICB) in: https://lesec.icb.ufg.br/ Acesso em: 01 de Jan. 2018. 